\title{
Oculo Orbital Complications of Sinusitis
}

\author{
Nada Otmani ${ }^{*}$, Serheir Zineb ${ }^{2}$, Housbane Sami², Oudidi Abdellatif ${ }^{1}$, \\ Bennani Othmani Mohamed² \\ ${ }^{1}$ Hassan II Hospital, Fez, Morocco \\ ${ }^{2}$ Faculty of Medicine, Casablanca, Morocco \\ Email: "nada.oudidi@gmail.com, abdellatif.oudidi@usmba.ac.ma,nada.otmani@usmba.ac.ma, \\ pr.oudidi@gmail.com, alanine@gmail.com
}

Received 17 December 2015; accepted 21 February 2016; published 24 February 2016

Copyright (C) 2016 by authors and Scientific Research Publishing Inc.

This work is licensed under the Creative Commons Attribution International License (CC BY). http://creativecommons.org/licenses/by/4.0/

cC) (i) Open Access

\section{Abstract}

The ocular-orbital complications of sinusitis constitute a diagnostic and therapeutic urgency that requires a correct multidisciplinary assumption. Objectives: The description of clinical and therapeutic data of the orbital complications of acute sinusitis. Methods: Our work is based on a retrospective study of 86 cases of ocular-orbital complications of sinusitis hospitalized at the ENTdepartment of Hassan II Hospital in Fes (Morocco), between the years of 2006 and 2014. Results: It is about 56 men and 30 women. The average age was 24 years, with the extremes of 3 years and 65 years. The average time of consultation was 13 dates. The achievement was frontal-ethmoido in 26 cases, and it is about a pan sinusitis in 24 cases. About $13 \%$ and $7 \%$ of cases were classified respectively in the stage III and the stage IV of chandler. The surgery was done for 24 cases. Bacteriological sample was performed among 24 patients and allowed to isolate a streptococcus $(3.5 \%)$, and a staphylococcus $(5.8 \%)$, and a poly microbial flora for $15.1 \%$ of patients. A death in sepsis panel was noted for a patient who presented a thrombosis of cavernous sinus. And we have noted a persistent left exophthalmia without the diminution of visual acuity for another patient. Conclusion: The orbital complications of sinusitis require a multi-disciplinary medical approach associated to ear specialist, ophthalmologist, and neuro-radiology. A precocious diagnosis, an appropriate anti-biotic therapy, and sometimes an associated surgical treatment, can significantly diminish the mortality and the morbidity related to this pathology.

\section{Keywords}

Oculo Orbital, Sinusitis, Complication, CT Scan, Endoscopic Surgery

\footnotetext{
*Corresponding author.
} 


\section{Introduction}

The ophthalmologic complications of chronic and acute sinusitis are more frequent than the cranial and endocranial complications [1] [2]. The severity of complications attached to the sinus infections resides in the risk of blindness by damage of the optic nerve. The vital prognosis can be included in the forms reaching the orbital apex, by the spread of infection towards the cavernous sinus and the cerebro-meningeal structures [3] [4].

Current thinking supports that the pathogenesis of these complications is predominantly a multifactorial inflammatory disease [1] [3]. The role of bacteria in the pathogenesis of these complications; is currently being reassessed. Repeated and persistent sinus infections can develop in persons with severe acquired or congenital immunodeficiency states or with a disruption of the intrinsic mucociliary transport system [5] [6].

Despite the fact that the incidence and the severity of these complications have been gradually diminished in recent years in the western countries, they continue to have a serious medico-surgical challenge in our society [1] [5]. Therefore, the objective of our study was to describe the clinic, bacteriologic and therapeutic characteristics of these lesions and their evolution.

\section{Patients and Method}

We bring a number of cases of the ocular-orbital complications of sinusitis, treated in the ENT department of Hassan II Hospital in Fes (Morocco) during a period of 10 years from January 2006 to September 2014.

The informations were collected from patients' records. The variables collected were about the demographic data, the front door, the time delay before consultation, the ocular-orbital complications observed, the result of bacteriological examination when it is performed, the performed treatment and long-term development. We used the classification of chandler to determine the different anatomic-clinical stages of orbital attacks. This classification is based on the extension inflammation in relation to the anatomic-physiological boundaries which are the septum and the periosteum by order of increasing severity. The different characteristics have been described as percentage except for age and the time delay before consultation for which the average and the extremes are related. The statistical analysis has been realized using the software Epi Info 3.5.1.

\section{Results}

During the period of study, 86 cases of ocular-orbital complications have been noted for the patients suffering from sinusitis. The average age of patients was 24 years, with the extremes from 3 years to 65 years with a male predominance (sex ratio of 3/1).

Concerning the antecedents, nine patients were diabetic (10.5\%), 27 had a chronic rhinitis and one patient had an antecedent of the old maxilla-facial trauma. Eight cases had chronic smocking.

The search of the sinus gateway, though hard to find at admission, helped us to note a rhinogenic cause in 34 cases (39.5\%), dental in three cases (3.4\%) and secondary to maxillofacial trauma in one case (1.1\%).

The consultation period has been précised for all patients and ranged from three days to 60 days with the median of 13 days.

\subsection{Clinical Features and Review}

Two thirds of patients (69\%) presented the first signs of sinus damage between September and February, which is the period of nasopharyngitis.

The eyelid edema and the periorbital pain were constant symptoms that lead the patients to consult (Figure 1). The ENT examination includes systematically a nasal endoscopy which helped to retain the sinus origin in front of mucosal inflammation, festering rhinorrhea and the nasal obstruction.

One of the patients was presented with a bilateral eyelid edema associated to the consciousness troubles. His neurological examination found a state of gradual mental clouding, and imagery found a thrombosis of cavernous sinus.

The contribution of ophthalmologists was very successful (Figure 2). Their clinic examination allowed to note an eyelid edema and a periorbital pain for all the patients associated with:

- An exophthalmia in 19 cases (22\%),

- A conjunctival redness in 11 cases (12.8\%),

- Chemosis in 11 cases (12.8\%),

- A mydriasis in one case (1.1\%), 


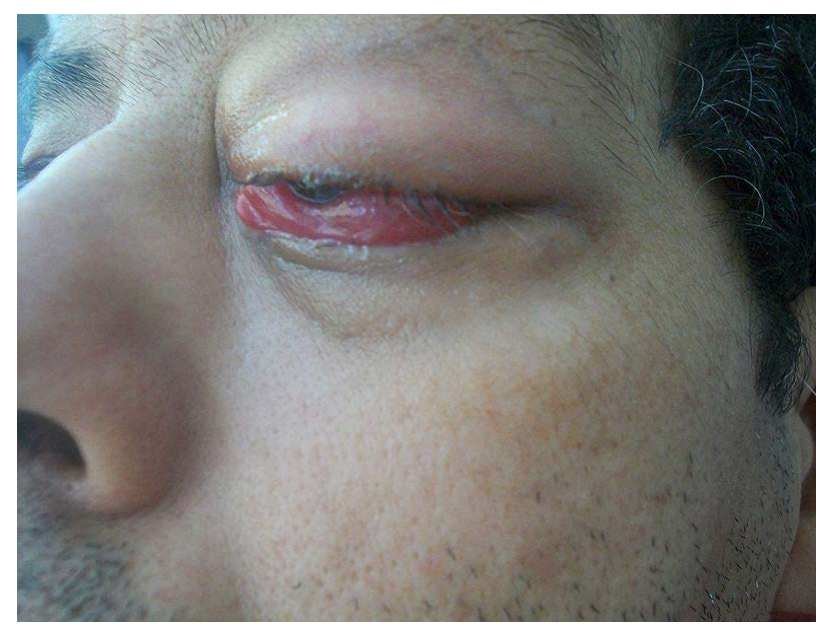

Figure 1. Orbital abscess secondary to a left frontal sinusitis.

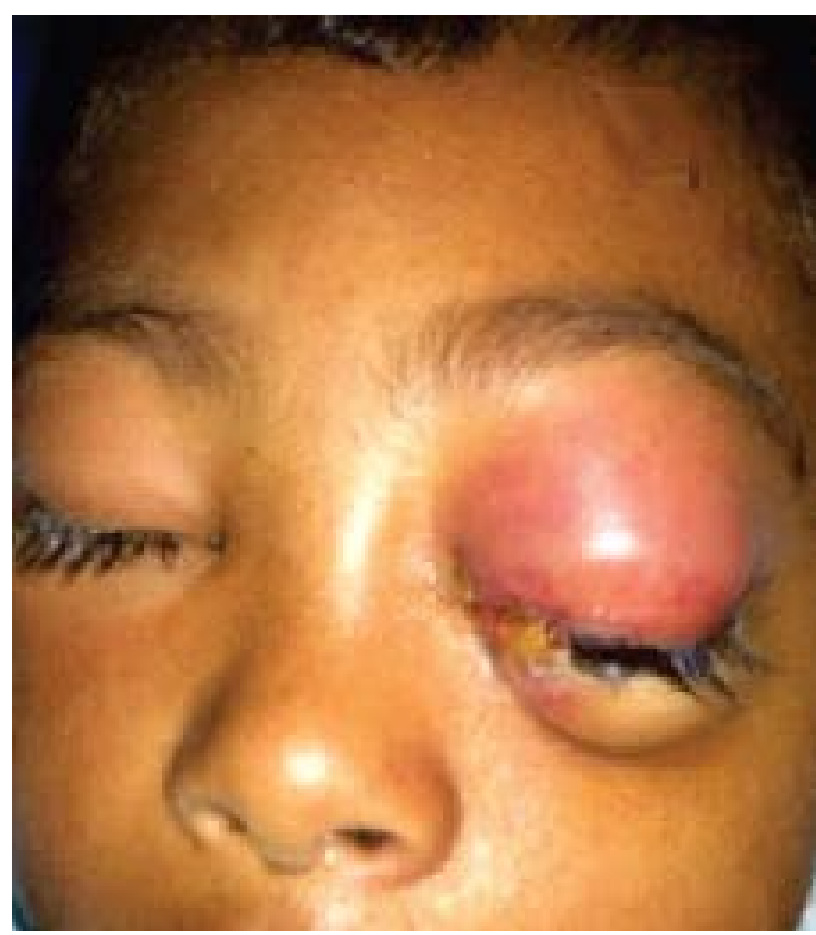

Figure 2. Orbital abscess secondary to a ethmoiditis.

- A squint in 1 case (1.1\%),

- Ocular Motility Disorders in five cases (5.8\%).

A decrease of visual acuity in 5 cases (5.8\%), two cases of blindness: one unilateral (a very pale ischemic papilla in a patient having a pan sinusitis), and the other in a patient with diabetic retinopathy.

\subsection{Imagery Results}

The ocular echography was done for 12 patients and returned normal in 7 cases and showed an orbital abscess collection in other cases.

The orbital-frontal brain and nasal sinus CT helped appreciating the siege and the extent of sinus damage and assessing the degree of orbital and intracranial complications (Figure 3). The frontal ethmoido sinusitis was the most frequent (30.2\%) followed by the pansinusitis (27.9\%) (Figure 4). 


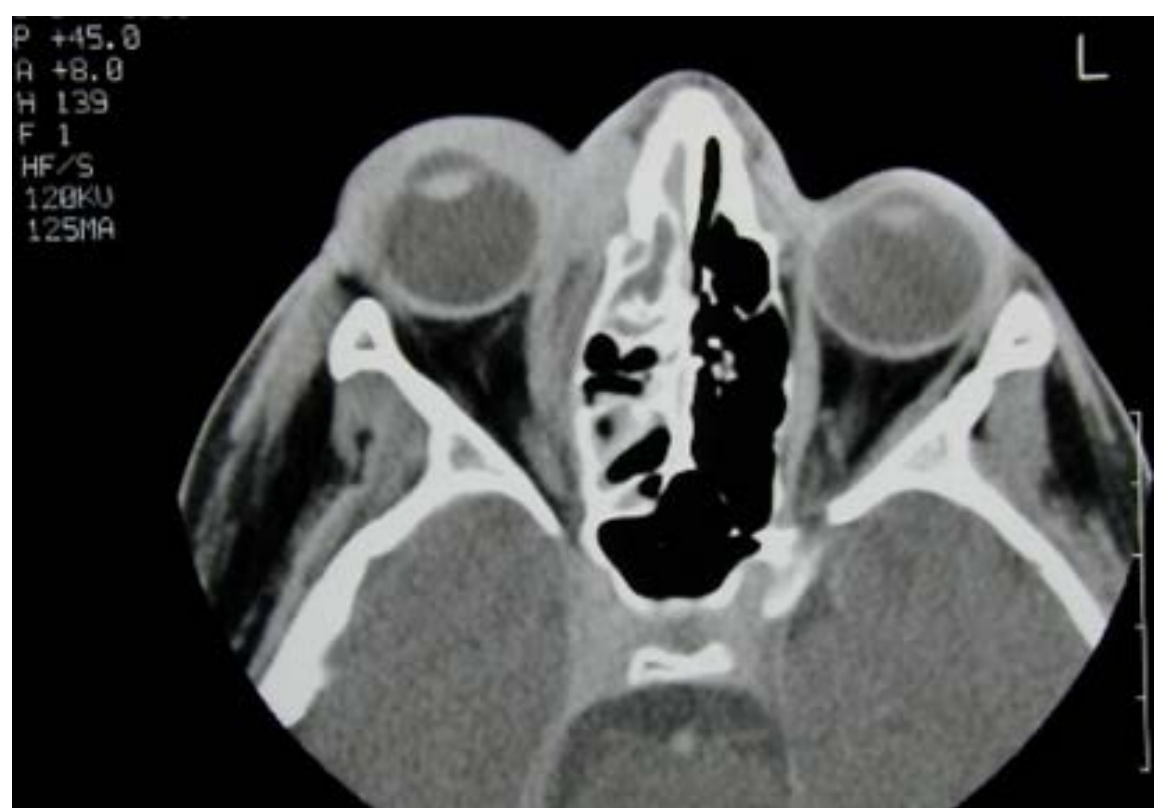

Figure 3. CT image in axial section showing a filling right ethmoid extended to the ipsilateral orbit with subperiosteal abscess and exophthalmia.

Different localizations of sinusitis

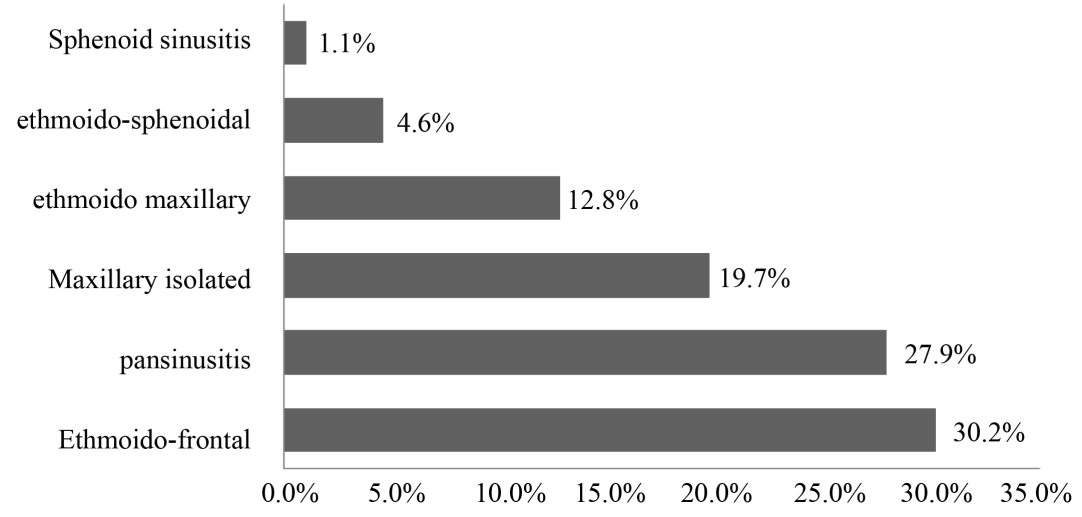

Figure 4. Landforms sinusitis.

Distribution of patients according to the classification of Chandler

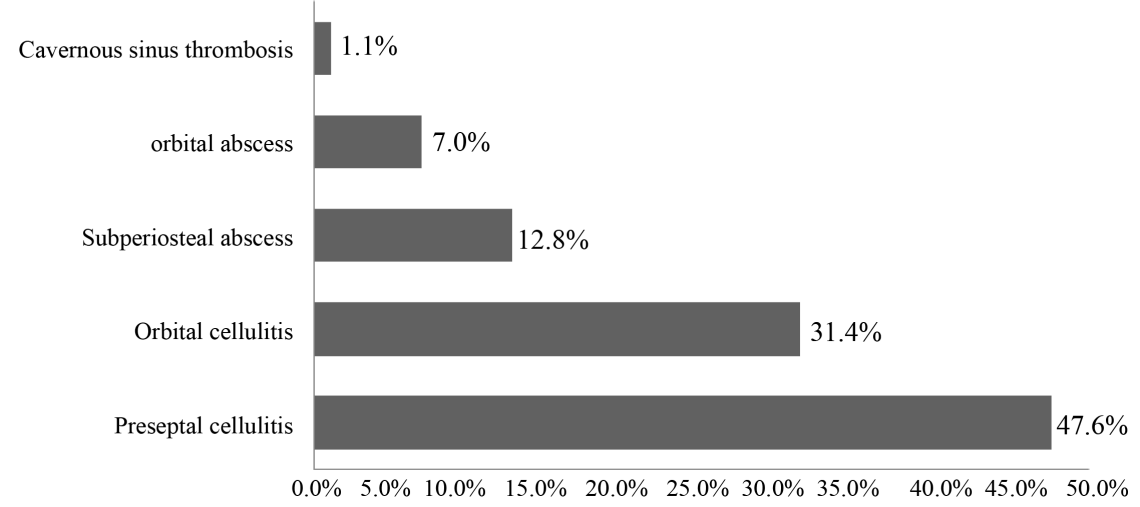

Figure 5. Distribution of patients according to the Chandler's classification. 
According to the Chandler's classification, the patients were divided into five stages: $47.6 \%$ had a preseptal cellulite, and 31.4\% had an orbital cellulite (Figure 5).

One single patient had an orbital fistula in addition to the preseptal cellulite. A diabetic patient unbalanced and having the chronic pan-sinusitis neglected, presented a hearth of intracranial suppuration.

\subsection{Biological Examination}

The biological assessment confirmed inflammatory nature showing a hyper-leucocytosis to neutrophil for 66 patients $(76.7 \%)$ with a very accelerated sedimentation rate for $59.3 \%$ of patients and an elevated CRP for $52 \%$ of patients. no blood culture was performed.

The HIV serology was requested for three patients whose clinical condition was very noisy, and it came negative.

The bacteriological examination to find the germ was performed for 24 patients (27.9\%). The sample was taken in consultation for a patient with left upper eyelid fistula, and to the operating block during orbital or sinus drainage for 23 cases. The result was in favor of a polymicrobial flora for 13 patients (15.1\%); no germ was found for 9 patients (10.4\%). The most frequent germs were staphylococcus aureus (5.8\%), streptococcus (3.5\%), Haemophilus (2.4\%) and Bacteroides (1.1\%).

\subsection{Support and Evolution}

During hospitalization, a medical treatment was administered for all patients, based on probabilistic broadspectrum antibiotic therapy by the parental route sometimes adjusted according to the antibiogram data when available. The length of antibiotic therapy was from 5 to 6 days for the orally injectable route relayed for two weeks. This treatment was associated with:

- A nasal local treatment (washing and trimming of the nasal cavity), in 27 patients or $31.4 \%$.

- An antibiotic collyrium in 19 cases, $20 \%$ of patients.

- An oral corticosteroid therapy of short length for 8 patients, 9.3\%.

Anticoagulant treatment was prescribed for curative dose in the case of cavernous sinus thrombosis.

The surgery was up every time which conveyed a compressive abscessed collection and before the medical treatment failure. It was performed for 21 patients (24.4\%). The surgical gesture consisted of:

- Drainage of orbital abscess in 6 cases, of which one is by endoscopic route and five by external route.

- Drainage of a subperiosteal abscess in one case, performed by endoscopic route.

- A decompressive orbitotomy in one case of orbital cellulite with the aggravation of ocular function.

- An average meatotomy associated to the anterior ethmoidectomy by endoscopic route for seven patients.

- Drainage of an abscess collection of soft parts in two cases.

- A biopsy (after drainage of orbital abscess) in one case.

- A dissection of the fistula in one case, with the curettage of the mucosa of correspondent sinus.

The surveillance under treatment was based on clinical signs (ophthalmologic, rhinologic, and neurologic) and the radiologic signs (the control scanner done in 3 cases). Regular monitoring was conducted for a year. Additionally, the patients consulted in need.

The decline of patients ranged from 14 months to 5 years with an average of 41 months. While monitoring, the patient who presented a carvenous sinus thrombosis passed away in a septicemia table. The persistence of left exophthalmia during eight months without diminution of visual acuity was noted for one patient of 52 years, who has refused the surgery for an abscess under periosteum.

Most of patients were male, with a median age of 24 years and about $11 \%$ were diabetic. The frontal-ethmoido damage was the most frequent (30.2\%) followed by pan-sinusitis (27.9\%). Almost (47.6\%) of patients presented a stage I of Chandler (preseptal cellulite) of the orbital complications of sinusitis, while about one third (31.4\%) of them had orbital cellulite (stage II). The bacteriological evaluation was generally in favor of polymicrobial flora. Staphylococcus aureus was the most germ found.

All patients have benefited from the antibiotic treatment associated to local treatment. The surgical treatment was performed for $24,4 \%$ of cases, before an abscess collection or treatment failure. The evolution was favorable for all patients, except for the patient having presented a carvenous sinus thrombosis, who died in a septicemia table.

\section{Discussion}

The ocular-orbital complications are the most frequent (80\%) of acute sinusitis complications [1] [3]. In fact 60 
to $75 \%$ of inflammatory damages of orbit are consecutive for sinusitis [3] [5]. The predominance of ophthalmological complications for children and young people is usually reported in the majority of the literature series [3] [5]-[7]. In the series of Lui the proportion was lower (38.7\%) [8].

The male predominance of the orbital complications of acute sinusitis was pointed out by most of the authors [1] [9] [10]. However, in the series reported by Ben Ammor [5], the female predominance was remarked. The immunosuppression is a favorable ground for complicated acute sinusitis [11]. Diabetes is considered as the most classic factor of immunosuppression and the most predisposing for carvenous sinus thrombosis [12]. The infection to VIH [11], medullary aplasia post chemotherapy, treatment by radiotherapy [3] [5] [10], the troubles of local nasal immunity and hypogammaglobulinaemia are also the causes of immunosuppression.

The bilateralization of ophthalmological signs is a factor of poor prognosis, and the visual function can be compromised. The cavernous sinus thrombosis generally includes vital prognosis [12] [13], but it can also appear by an isolated paralysis of VI and simply chemosis and/or ptosis [11] [13].

In most studies, the preseptal cellulites were the most frequently encountered complications [8] [10]. A study conducted in Tunisia [14] proved that about half of the patients presented subperiosteal abscesses.

The ophthalmological complications of acute sinusitis are most often secondary to ethmoiditis [4] [15] [16]. The orbital sonography is effective for the study of the lesions located in front of the orbit and is less efficient in the regions of apex and the back of eyeball. This examination maintains its interest in monitoring under medical treatment abscesses [3] [5] [16] [17]. Furthermore, cerebral CT performed with and without the injection of the contrast material allows searching for possible signs in favor of cavernous sinus damage, or the indirect orbital signs. The RMN is essentially requested before a suspected intracranial spread of infection [6] [18] [19]. It is less available in urgency, and it has not totally replaced the scanner for the initial diagnosis of sinusitis complications, but becomes the choice of examination for monitoring. It is more efficient than scanner in the diagnosis of venous thrombosis, its evolution, and of possible associated parenchymal lesions.

The germs involved are mainly aerobic bacteria. The anaerobic germs will be found in association in $43 \%$ of cases, most frequently isolated for adults [5] [10]; they are probably under-estimated infrequency and require an appropriate research in order to adapt the treatment [2] [20] [21]. Some germs seem to present a significant aggressiveness as evidenced by the rapid evolution towards complications. However, the increasing resistances to antibiotic treatment in the first intention must be evoked primarily [3] [14] [15]. For certain authors, the staphylococcus aureus, the streptococcus, anaerobes are most often responsible for orbital complications [21] [22]. For most authors, the common causative organism of carvenous sinus thrombosis is staphylococcus aureus [12] [22]. And the progression towards irreversible blindness is possible in case of methi-resistent staphylococcus aureus [22]. The poly-microbial damage is frequent; especially for adults. The aspergillosis of maxillary sinus on a foreign body of dental origin is the most classical picture of fungal sinusitis [5] [21].

According to Klosselk [4], the patients in the stage I of Chandler can be outpatients. The hospitalizations with an ophtalmological examination, a bacteriological levy, an antibiotic treatment by venous lane are recommended for the stages II, III, IV, and V [4] [23] [24].

The frequency of these complications has been decreased significantly with the advent of new antibiotic molecules [1] [6]. The therapeutic management of sinusitis complications is an urgency, which still relies on a probabilistic broad-spectrum antibiotic therapy, active against the main usual bacteria (aerobic and anaerobic) in the foreground [24]-[26], associated or not to a surgical treatment [1] [17] [25], and undertaken as soon as the samples are done [6] [24]-[26]. This treatment must be adapted secondly in terms of bacteriological results [3] [6] [25] [26]. The duration of intravenous antibiotic therapy is from 5 to 10 days with oral relay soon as apyrexia is durable, and after the disappearance of local inflammatory signs, and it must last between 10 and 15 days [15] [24] [26].

The local treatments are important to facilitate airing and the sinus drainage. This treatment is always necessary. The use of corticoids is very controversial. Some authors advocate corticoids before a suspicion of the optic nerve infringement with the decrease of visual acuity [5]. It has a short duration that ranges from 5 to 6 days [27].

In case of thrombophlebitis; heparin therapy is recommended by some authors [8] [12] and discussed by some others [24] [27]. A randomized clinical attempt confirmed without ambiguity, the benefit of aspirin on the vital and the functional prognosis of the patient. Even in case of the presence of cerebral hemorrhagic lesions [15].

The surgical orbital drainage, using a bacteriological examination, is indicated before tomodensitometric examination of an orbital collection or before the clinical aggravation under treatment [6] [15]. It must be per- 
formed in urgency, in order to avoid having serious complications, such as optic nerve compression or of the cavernous sinus thrombosis [12] [28].

The sinus drainage is also systematic. It often helps ameliorating drainage and ventilation of the cells of anterior ethmoid, eliminating the inflammatory pathology which causes the obstruction of drainage tract [5] [15]. The surgical drainage allows having, in good conditions, often difficult bacteriological samples, or impossible to perform in consultation, to open the sinuses widely, and to wash, and to drain. However, since the advent of endoscopic equipments, the endoscopy is becoming increasingly widespread and sets two objectives [23] [28] [29]; the creation of a wide communication between sinuses and nasal pits, and the maximum preservation of anatomy and respiratory mucosa. However, the endoscopic route is not recommended for the pediatric patients, view of the ethmoid size. Thus, the increased risk of the post-operatory complications.

The Endonasal endoscopic surgery allows for a functional gesture of sinonasal cavities while preserving the physiological properties of the lining and providing nasal and sinus ventilation. It allows to limit complications and disfigurement external routes. Its development required the creation of an appropriate instrumentation. Thus the videosurgery, took his booming, making possible the operating comfort, better control gestures and unparalleled quality of teaching [23] [29].

It is noteworthy that even an earlier and aggressive surgical treatment does not ensure the prevention of ocular sequela. Harris [30] reported a sequelar blindness incidence of $14 \%$ and Spires an incidence of 33\% [31]. Hence, the preventive treatment of complicated acute sinusitis must go through the management of viral rhinopharyngitis since they constitute the front door of sinusitis in most cases, and therefore that of complications. No study to date has investigated the role of vaccines through the general route in preventing the acute rhino-sinus infection of the child [32]. It is likely that the Hib conjugated vaccines (1992) and Heptavalent conjugated pneumococcus are induced by reducing the nasopharyngeal carriage of vaccine serotypes and their transmission, an individual but also collective protection [31] [33].

The pre-septal cellulites, the orbitals, and the sub-periosteal abscesses often have a favorable development without sequella under medical treatment [5] [24]. Yet we can sometimes remark a clinical aggravation (the decrease of visual acuity) in case of sub-periostal abscess. The indication of drainage is formal at this stage [9] [21] [30].

The visual prognosis is strongly undermined despite the urgent establishment of a surgical and medical treatment of intra-orbital abscess. The evolution may do so towards a carvenous sinus thrombosis or a cerebral abscess, bringing into play the vital prognosis [12] [21] [31].

The cavernous sinus thrombosis was a frequent pathology whose mortality is $100 \%$ [3] [6]. With the antibiotic treatment, this rate is actually reduced to attain the percentage between $23 \%$ and $50 \%$ with the neurologic and the ophthalmologic sequela in over half of the cases [3] [6] [9]. The recurrences of ophthalmologic complications must seek an endonasal anomaly; detect a mucoviscidosis or an allergic terrain [31].

The prevention of these complications passes through proper treatment planning. This should include a thorough clinical examination, detailed history taking, and appropriate imaging. In addition to a proper medical history, it is appropriate to take a history of sinus disease, predisposition to colds and sinusitis, as well as a history of any operations that might have been carried out. The immunotherapy reduces the reaction of body against allergens and treats the infection [6] [21].

\section{Conclusions}

The ocular-orbital complications are rare but severe. Their diagnosis must be urgent and adaptable due to the serious consequences.

Clinical signs help us to determine the type of complications and to evaluate the degree of severity. Imagery confirms diagnosis.

Management is based on a parenteral antibiotic therapy which is mostly directed against the key germs presumed in these conditions. The cooperation of ENT specialists, ophthalmology and radiology is often helpful.

The surgical treatment can be associated in case of an abscessed collection. The radiological and clinical surveillance is unavailable.

\section{Acknowledgements}

The accomplishment of this manuscript benefits of the help and direction from my dear supervisor-Prof. A Oudidi. Prof. Oudidi is always happy and willing to help me solve the confusions and direct me approach to the fi- 
nal result of the study. Without his encouragement, I would not finish this final work. Furthermore, I would like to show my grateful feeling to Prof. Bennani, with whose supervision I accomplish my study in time. He is always patient to help me out with questions in terms of administration and rules.

\section{Competing Interests}

The authors declare that they have no competing interests.

\section{Authors' Contributions}

1) NO: contributions to conception and design, and acquisition of data.

2) $\mathrm{AO}$ and $\mathrm{SH}$ : analysis and interpretation of data.

3) ZS: participate in drafting the article and revising it critically for important intellectual content.

4) BOM: give final approval of the version to be submitted and any revised version.

\section{References}

[1] Chahed, H., Bachraoui, R., Kedous, S., Ghorbel, H., Houcine, A., Mediouni, A., Marrakchi, J., et al. (2014) Management of Ocular and Orbital Complications in Acute Sinusitis. Journal Français d'Ophtalmologie, 37, 702-706. http://dx.doi.org/10.1016/j.jfo.2014.02.010

[2] Souldi, H., Bouchareb, N., Khassime, S., Abada, R., Rouadi, S., Mahtar, M., et al. (2013) Complications OculoOrbitaires des sinusites aiguës. Ann Fr Oto-Rhino-Laryngol Pathol Cervico-Faciale, 130, A124.

[3] Belhoucha, B., Hssaine, K., Rochdi, Y., Nouri, H., Aderdour, L. and Raji, A. (2014) Les complications oculo-orbitaires des sinusites : Etude prospective à propos de 20 cas. Ann Fr Oto-Rhino-Laryngol Pathol Cervico-Faciale, 131, A158A159. http://dx.doi.org/10.1016/j.aforl.2014.07.370

[4] Klossek, J.-M., Quinet, B., Bingen, E., François, M., Gaudelus, J., Larnaudie, S., et al. (2007) État actuel de la prise en charge des infections rhinosinusiennes aiguës de l'enfant en France. Médecine et Maladies Infectieuses, 37, 127-152. http://dx.doi.org/10.1016/j.medmal.2006.11.008

[5] Ben Amor, M., Khalifa, Z., Romdhane, N., Zribi, S., Ben Gamra, O., Mbarek, C., et al. (2013) Les complications orbitaires des sinusites. Journal Français d'Ophtalmologie, 36, 488-493. http://dx.doi.org/10.1016/j.jfo.2012.06.027

[6] Sova, J. and Raczyńska, K. (2004) Ocular and Orbital Complications of Paranasal Sinusitis. Klin Oczna, 106, 525-527.

[7] Nwaorgu, O.G.B., Awobem, F.J., Onakoya, P.A. and Awobem, A.A. (2004) Orbital Cellulitis Complicating Sinusitis: A 15-Year Review. Nigerian Journal of Surgical Research, 6, 14-16.

[8] Liu, I.-T., Kao, S.-C., Wang, A.-G., Tsai, C.-C., Liang, C.-K. and Hsu, W.-M. (2006) Preseptal and Orbital Cellulitis: A 10-Year Review of Hospitalized Patients. Journal of the Chinese Medical Association, 69, 415-422. http://dx.doi.org/10.1016/S1726-4901(09)70284-9

[9] Oxford, L.E. and McClay, J. (2006) Medical and Surgical Management of Subperiosteal Orbital Abscess Secondary to Acute Sinusitis in Children. International Journal of Pediatric Otorhinolaryngology, 70, 1853-1861. http://dx.doi.org/10.1016/j.ijporl.2006.05.012

[10] Ryan, J.T., Sumit, B. and Preciado, D.A. (2008) Orbital Cellulitis in 465 Children: A Review of 465 Cases. Otolaryngology—Head and Neck Surgery, 139, P162. http://dx.doi.org/10.1016/j.otohns.2008.05.436

[11] Del Borgo, C., Del Forno, A., Ottaviani, F. and Fantoni, M. (1997) Sinusitis in HIV-Infected Patients. Journal of Chemotherapy, 9, 83-88. http://dx.doi.org/10.1179/joc.1997.9.2.83

[12] Nagi, C.K. (2008) Thrombose de la loge caverneuse secondaire à une sinusite: Cavernous sinus thrombosis secondary to sinusitis. Journal of Radiology, 89, 803-805. http://dx.doi.org/10.1016/S0221-0363(08)73787-9

[13] Chandler, J.R., Langenbrunner, D.J. and Stevens, E.R. (1970) The Pathogenesis of Orbital Complications in Acute Sinusitis. The Laryngoscope, 80, 1414-1428. http://dx.doi.org/10.1288/00005537-197009000-00007

[14] Chahed, H., Bachraoui, R., Kedous, S., Ghorbel, H., Houcine, A., Mediouni, A., et al. (2014) Prise en charge des complications oculo-orbitaires des sinusites aiguës. Journal Français d'Ophtalmologie, 37, 702-706. http://dx.doi.org/10.1016/j.jfo.2014.02.010

[15] Ozkurt, F.E., Ozkurt, Z.G., Gul, A., Akdag, M., Sengul, E., Yilmaz, B., et al. (2014) Managment of Orbital Complications of Sinusitis. Arquivos Brasileiros de Oftalmologia, 77, 293-296. http://dx.doi.org/10.5935/0004-2749.20140074

[16] Khaled, H., El korbi, A., Belhadj Rhouma, S., Chouchène, H., Kolsi, N. and Koubaa, J. (2014) Complications orbitaires des sinusites: Diagnostic et prise en charge thérapeutique. Annales Françaises d'Oto-Rhino-Laryngologie et 
de Pathologie Cervico-Faciale, 131, A155. http://dx.doi.org/10.1016/j.aforl.2014.07.360

[17] Dessi, P., Champsaur, P., Paris, J. and Moulin, G. (1999) Imaging of the Adult Sinusitis: Indications for Using Conventional Techniques, CT Scan and MRI. Revue de Laryngologie Otologie Rhinologie, 120, 173-176.

[18] Grimbert, P., Vabres, B., Orignac, I., Lebranchu, P., Clairand, R., Gayet, M., et al. (2013) Intérêt diagnostique d'une réunion de concertation multidisciplinaire des pathologies orbitaires inflammatoires au CHU de Nantes. Journal Français d'Ophtalmologie, 36, 809-814. http://dx.doi.org/10.1016/j.jfo.2013.02.009

[19] Idrissi, I.A., El Benna, N., Ouardi, F. and Abdelouafi, A. (2009) Imagerie des complications orbitaires de la pathologie naso-sinusienne. Journal de Radiologie, 90, 1563-1564. http://dx.doi.org/10.1016/S0221-0363(09)76128-1

[20] Brook, I. (2009) Microbiology and Antimicrobial Treatment of Orbital and Intracranial Complications of Sinusitis in Children and Their Management. International Journal of Pediatric Otorhinolaryngology, 73, 1183-1186. http://dx.doi.org/10.1016/j.ijporl.2009.01.020

[21] Kim, H.J. (2004) Clinical Analysis of Orbital Complications of Acute Sinusitis in Children and Adults. OtolaryngologyHead and Neck Surgery, 131, P258. http://dx.doi.org/10.1016/j.otohns.2004.06.529

[22] Rutar, T., Zwick, O.M., Cockerham, K.P. and Horton, J.C. (2005) Bilateral Blindness from Orbital Cellulitis Caused by Community-Acquired Methicillin-Resistant Staphylococcus aureus. American Journal of Ophthalmology, 140, 740742. http://dx.doi.org/10.1016/j.ajo.2005.03.076

[23] Ikeda, K., Oshima, T., Suzuki, H., Kikuchi, T., Suzuki, M. and Kobayashi, T. (2003) Surgical Treatment of Subperiosteal Abscess of the Orbit: Sendai’s Ten-Year Experience. Auris Nasus Larynx, 30, 259-262. http://dx.doi.org/10.1016/S0385-8146(03)00060-9

[24] François, M., Mariani-Kurkdjian, P., Dupont, E. and Bingen, E. (2006) Ethmoïdites aiguës extériorisées de l'enfant: A propos d’une série de 125 cas. Archives de Pédiatrie, 13, 6-10. http://dx.doi.org/10.1016/j.arcped.2005.09.032

[25] Société de pathologie infectieuse, Société française de pédiatrie, Société française d'ORL and Collège Francais d'ORL (1996) Les infections ORL. Revue Médicale de l'Assurance Maladie, 4, 4-10.

[26] Chidiac, C. (2011) Antibiothérapie par voie générale dans les infections respiratoires basses de l'adulte. Médecine et Maladies Infectieuses, 41, 221-228. http://dx.doi.org/10.1016/j.medmal.2010.10.001

[27] Wane, A.M., Ba, E.A., Ndoye-Roth, P.A., Kameni, A., Demedeiros, M.E., Dieng, M., Ndiaye, M.R., et al. (2005) Senegalese Experience of Orbital Cellulitis. Journal Français d'Ophtalmologie, 28, 1089-1094. http://dx.doi.org/10.1016/S0181-5512(05)81143-X

[28] Teinzer, F., Stammberger, H. and Tomazic, P.V. (2015) Transnasal Endoscopic Treatment of Orbital Complications of Acute Sinusitis: The Graz Concept. Annals of Otology, Rhinology \& Laryngology, 124, 368-373.

[29] Facon, F. and Dessi, P. (2005) Chirurgie endonasale micro-invasive: Apport de l'endoscopie en chirurgie maxillofaciale: Rapport pour le 41e Congrès français de Stomatologie et Chirurgie Maxillo-Faciale Marseille, 21-23 septembre 2005. Revue de Stomatologie et de Chirurgie Maxillo-Faciale, 106, 230-242. http://dx.doi.org/10.1016/S0035-1768(05)85852-8

[30] Harris, G.J. (1994) Subperiosteal Abscess of the Orbit. Age as a Factor in the Bacteriology and Response to Treatment. Ophthalmology, 101, 585-595. http://dx.doi.org/10.1016/S0161-6420(94)31297-8

[31] Spires, J.R. and Smith, R.J. (1986) Bacterial Infections of the Orbital and Periorbital Soft-Tissues in Children. The Laryngoscope, 96, 763-767. http://dx.doi.org/10.1288/00005537-198607000-00012

[32] Capra, G., Liming, B., Boseley, M.E. and Brigger, M.T. (2015) Trends in Orbital Complications of Pediatric Rhinosinusitis in the United States. JAMA Otolaryngology—Head \& Neck Surgery, 141, 12-17. http://dx.doi.org/10.1001/jamaoto.2014.2626

[33] Lindstrand, A., Bennet, R., Galanis, I., Blennow, M., Ask, L.S., Dennison, S.H., et al. (2014) Sinusitis and Pneumonia Hospitalization after Introduction of Pneumococcal Conjugate Vaccine. Pediatrics, 134, e1528-e1536.

\section{List of Abbreviations}

CT: Computed Tomography,

NMR: Nuclear Magnetic Resonance,

ENT: Ear, Nose and Throat. 